\title{
Is Perception The Missing Link Between Personality Traits And Student Performance?
}

Marcus D. Odom, (mdo0022@usl.edu), University of Southwestern Louisiana Hamid Pourjalali, (hamid@busadm.cba.hawaii.edu), University of Hawaii at Manoa

\begin{abstract}
Recent interest in the development and use of expert systems and computer-assisted instruction as pedagogical tools has resulted in a need for research into the effectiveness of such instructional methods. Prior studies have examined the effect of personality traits on knowledge development, both separate from and in cohort with a specific teaching method. Their results indicate that both personality traits and teaching method (classroom instruction and the use of an expert system), affect the development of declarative and procedural knowledge. Also, their results show that certain personalities prefer certain teaching methods. Other prior studies have shown that the perceptions of a teaching method can also influence students' performance in the classroom. The present research also support these findings. In addition, that personality traits affect perception has also been shown. Thus, the present research suggests that all three--personality traits, teaching method, and the perception of the teaching method--affect the development of knowledge with perception being the missing link between personality traits and performance. However, the results also show that students' perceptions of a teaching method do not necessarily harmonize with their performance, i.e., that a teaching method rated highly by students may not produce the best performance outcomes.
\end{abstract}

Introduction

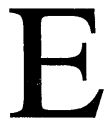
xpert systems are computer programs designed to emulate the analysis (thinking) process an expert uses in reaching a judgment regarding a particular problem. One area of tremendous potential for expert systems is as a tool to facilitate the education process. This pedagogical value is beginning to be recognized in the literature (Barbera, 1987).

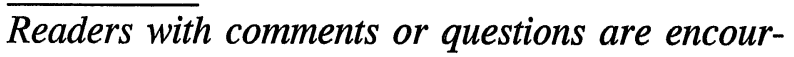
aged to contact the authors via e-mail.
Odom and Pourjalali (1996) evaluated the pedagogical value of expert systems by measuring the development of declarative and procedural knowledge in groups of students that learned a task by 1) using an expert system only, 2) having classroom instruction only, or 3) having a combination of classroom instruction and an expert system. In addition, they also considered the effect of each individual's personality traits on the effectiveness of the different teaching methods. They found that using an expert system significantly affected the development of 
declarative and procedural knowledge. Further evidence that the student's personality traits affected learning while using an expert system was also noted. This suggests that the problemsolving and information-processing behavior of an individual, along with habits and strategies, plays an important role in the decision-making process.

An earlier study, Boer and Livnat (1990), found that a subject's perception of a task may be negatively influenced by the fact that the task was performed using an expert system. An interesting finding in their study was that this negative influence resulted even though the subjects using the expert system performed better than subjects that used more traditional methods.

This study is an extension of Odom and Pourjalali (1996), introducing the possible effect of the students' perceptions of the different teaching methods on performance. These perceptions may provide a missing link between the students' performance on a task and the students' personality traits. This linkage between the students' personality traits and the students' perception of a teaching method may work in cohort to influence the students' performance while using different teaching methods.

The following section reviews selected literature on expert systems, knowledge types, and personality traits. The hypotheses development is discussed in section three, followed by the research design and empirical results in sections four and five. The conclusion contains a summary and is followed by suggestions for future research.

\section{Literature Review}

Expert systems technology makes it possible to expand the use of computers to broaderbased knowledge/judgment areas than has historically been possible. Expert systems, used as training devices offer the learner a highly flexible and realistic environment. They also provide a high degree of individualization in the training process in terms of speed, location, and trainee approach.

A potential user should understand the capabilities and the types of problems for which an expert system is best suited prior to using the tool. Expert systems are best suited for problems with 1) a complex and lengthy set of rules, 2) a set of rules that can be readily divided into small segments, 3) routines that need practice to be mastered fully, and 4) an ordering of the set of rules in the decision process. Some potential accounting applications of expert systems include audit and tax planning, internal control and accounts attribute analyses, quality reviews, decision making, management consulting, and teaching. Boer and Livnat (1990) identified transfer pricing as one topic suitable for using expert systems. This is the subject domain used by Odom and Pourjalali (1996).

An educational system is designed to facilitate the learning process. Gagne (1985) defines two types of knowledge--declarative knowledge and procedural knowledge--which are developed during the learning process. Declarative knowledge is factual knowledge, and procedural knowledge is the knowledge of how to do something. To be effective, the educational process should be designed to facilitate learning at both levels. Therefore, research studies that evaluate the use of expert systems for pedagogical use must consider the effect of using expert systems on both types of knowledge.

People have measurable differences in personality traits and it is highly possible that these differences will affect their learning processes. Waner and Echternacht (1993) found such differences in that the personality types and the preferences of those who teach office occupations and those who work as office professionals are significantly different. They found that the ones who teach the subject are more comfortable with factual (declarative) knowledge than with how-to-do (procedural) knowledge. Odom and Pourjalali (1996) also suggest a relationship between personality traits and learning 
that may affect the educational process. Additionally, Booth and Winzar (1993) suggest that accounting educators should cater to the variety of personality types among their students by adopting a diversified teaching approach.

One widely used instrument for typing people is the Myers-Briggs Type Indicator (MBTI) (Briggs and Myers, 1990). The MBTI, based on Jung's (1923) theory of psychological types, reports one's preferences on four basic scales. Individuals with different MBTI scores are interested in different things, drawn to different fields, and often find it difficult to understand each other. Myers and McCaulley (1989) discuss the four aspects of an individual's personality which are measured by the MBTI indicator: (1) how one is oriented toward the outside world, (2) how one prefers to take in information, (3) how one likes to make decisions, and (4) how quickly one comes to a decision. Each of these aspects has two extremes as outlined by Myers (1987) and discussed below.

The MBTI defines the first aspect of personality based on one's orientation toward the outside world. Extroverted (E) types tend to use the outer world as a source of concepts and ideas. They tend to be more comfortable working with people. Introverted (I) types look for the source of their concepts and ideas in their inner world. They tend to be more comfortable when the work involves ideas (Ott, Mann, and Moores, 1990).

The second aspect of personality classifies people as either Sensing (S) or Intuitive (N) in the way they absorb information. Individuals who are realistic and practical, accepting and working with what is "given" in the here-andnow, are classified as 'sensing' types. They are good at remembering and working with a great number of facts. Individuals who view information as being beyond their senses and who look at the big picture to grasp the essential patterns are classified as 'intuitive' types. They become expert at seeing new possibilities and new ways of doing things and value imagination and inspi- ration.

The way one likes to make decisions is represented by the third personality aspect. If individuals predict the logical consequences of any particular choice or action, they are classified as Thinking ( $\mathrm{T}$ ) types. These individuals seek an objective standard of truth and are frequently good at analyzing what is wrong with something. A Feeling (F) type considers what is important to themselves or to others and decide based on person-centered values, regardless of logic. They enjoy dealing with people and tend to become sympathetic, appreciative, and tactful.

How quickly one comes to a decision, the fourth aspect of personality, describes people as Perceiving (P) or Judging ( $\mathrm{J})$. 'Perceiving' types prefer work that requires adapting to changing situations. They try to understand, as opposed to managing, the situation. This type likes flexibility so a structured task may not be appealing. 'Judging' describes the process a person uses in structuring his or her work and personal life. These individuals prefer a structured work plan.

This study will address the relationship between the students' personality traits and their perceptions of teaching methods. The effect of this relationship on the students' learning abilities at both declarative and procedural levels will be examined. The findings of this study should provide evidence of a possible linkage which has not been fully addressed in prior studies.

\section{Hypothesis Development}

As pedagogical aids, expert systems might be better suited for students with particular personality types. An expert system guides the user through a decision-making process using queries to arrive at a solution to a problem within a particular situation. Depending on the expert system, the user may or may not be provided with the underlying facts and processes used in arriving at the solution. Most expert systems allow the user to view these facts and processes 
upon request, if such information is not provided automatically. Additionally, using expert systems may also affect a student's perceptions of an assignment and this affect may be different depending upon the student's personality traits.

The use of an expert system as a teaching method and a student's personality traits each have been shown to significantly effect the development of both declarative and procedural knowledge (Odom and Pourjalali, 1996). However, the role that the student's perception of the use of an expert system plays in the learning process nor any possibilities of a linkage between perception and personality traits are addressed in their study. Figure 1 provides a framework for discussing the effects of teaching method, personality traits, and perception of the teaching method on the development of declarative and procedural knowledge.

If perception is affected by both teaching method and personality traits, a better understanding of these relationships could facilitate the introduction of new teaching methods. It could provide an instructor, who is introducing a new teaching method, an opportunity to foresee and combat negative reactions from the students that may be caused by their particular personality traits. In addition, this link between personality traits and perception may be useful in understanding and explaining negative student evaluations of a course in which a new teaching method is implemented. Consequently, concerning the effect of the student's perception, the following hypotheses can be tested (stated in the null form):

H1: The perception of an assignment is not different when an expert system is used as a teaching method.

Based upon previous findings, the expectation is that the student's perception will be affected by the use of an expert system as a teaching aid. Prior research has found that the affect is a negative one.
H2: The students' personality traits will make no difference in their perception of an assignment.

The personality type research would suggest that certain personality types will accept different teaching methods in varied ways. Based on the first aspect, 'extroverted' individuals would appear to prefer a teaching method that allows more interaction with the instructor, whereas 'introverted' individuals would prefer less interaction, i.e. an expert system. Concerning the second personality aspect, 'sensing' individuals may prefer traditional instructional methods. 'Intuitive' individuals being open to new techniques and desiring patterns may prefer the expert system as a pedagogical tool. The 'thinking' individuals would probably go for expert systems based on the logic provided with the tools. 'Feeling' individuals, on the other hand, would probably feel more comfortable with a traditional method. Lastly, 'perceiving' individuals prefer work that requires adapting to a changing situation (here, the expert-system teaching method). Although 'judging' people like a more structured work plan (which an expert system is), they are averse to the change in their usual environment.

H3: The students' perception of a teaching method will make no difference in the performance on an assignment.

Based upon previous findings, Odom and Pourjalali (1996), that personality traits do affect performance, the expectation is that the student's perception will affect their performance. Perception may be the missing link between personality traits and performance. If an individual's personality traits affects their perception of a particular teaching method, then perhaps this perception is the factor that affects performance.

\section{Experimental Method}

Task 


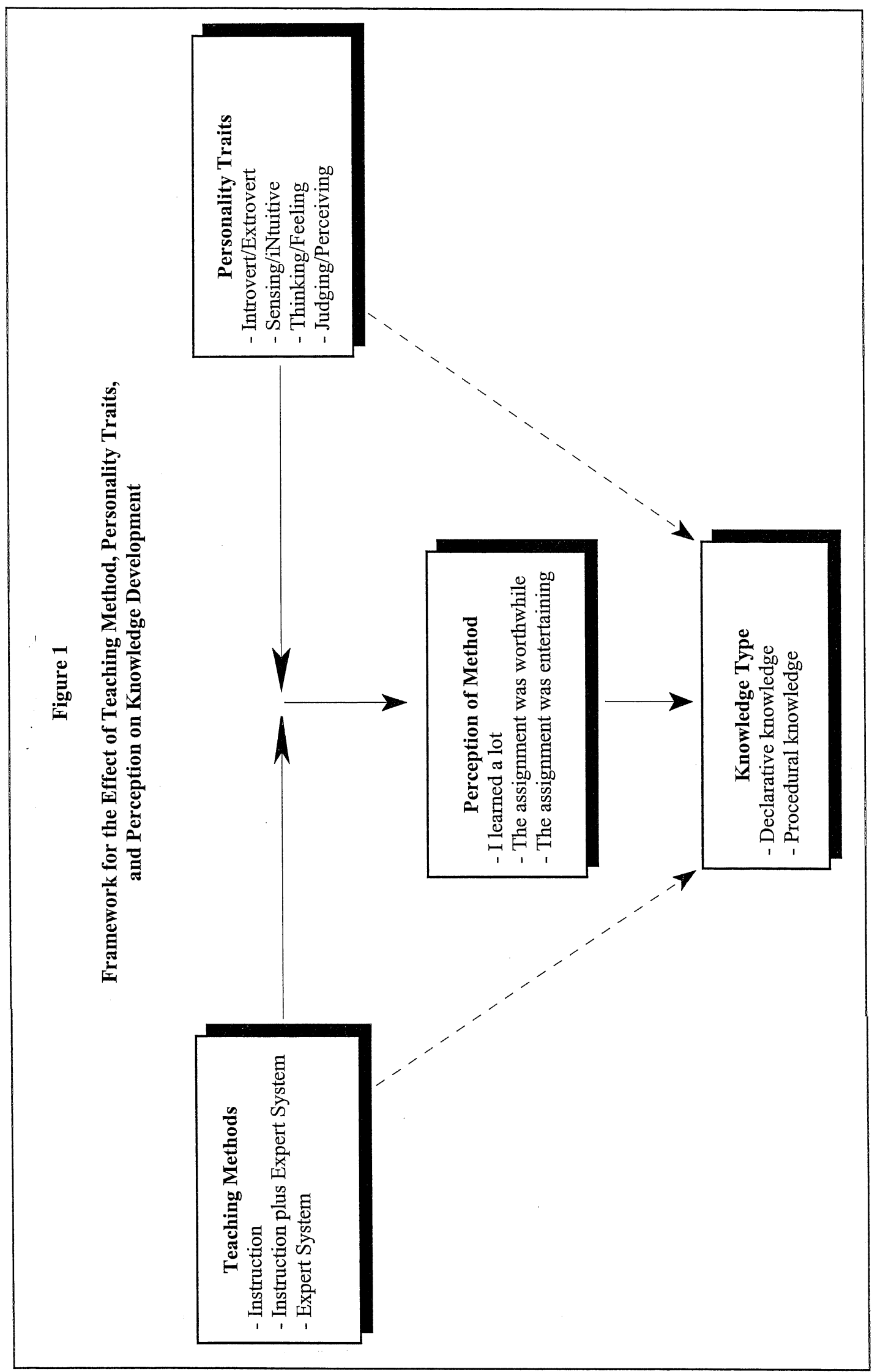


pricing cases in this experiment. Transfer pricing has been suggested as a viable topic for expert system-based instruction (Boer and Livnat, 1990) because such cases require analysis of a complex set of rules that can be easily divided into small segments and then analyzed in sequence during the decision-making process. The rules for the transfer pricing expert system were derived from Thomas' (1991) matrix approach to transfer pricing and were implemented using a rule-based expert system shell with a series of IF-THEN statements. Some subjects were given an expert system to use in completing the cases while others were given only a manual matrix decision aid. The subjects using the expert system had the option of viewing the rules and the reasons for the queries made by the expert system. These subjects could also look at a complete explanation of the solution path after they completed the session. The matrix-only subjects received no feedback.

\section{Subjects}

Ninety-seven students from three sections of an undergraduate managerial accounting course taught by the same instructor participated in this study ${ }^{1}$. This course is a sophomore-level course required for several majors. Treatments were randomly assigned to course sections, and not to individual students. Consequently, group sizes were uneven. The students completed a demographic questionnaire, which was used to test for homogeneity of the sections. These demographic variables were also tested for use as covariates in the analysis.

Pre-test

All three sections were given a pre-test to measure the students' knowledge of transfer pricing prior to the treatment. The pre-test consisted of two parts: (1) ten questions designed to measure the declarative knowledge and (2) six transfer pricing problems for measuring baselevel procedural knowledge. The subjects were required to act upon the information presented, that is, to use procedural knowledge in solving these problems. Both parts of the pre-test were given prior to any instruction and completed without any decision-making aids. The ten questions were fact-based questions on transfer pricing taken from managerial accounting textbooks and test banks. The transfer pricing problems were from managerial accounting textbooks and were selected to cover many possible scenarios within the transfer pricing area. The problems varied from simple to more difficult problems.

\section{Cases}

After completing the pre-test, the subjects received the "Instruction-only," "Instruction-with-Expert-System," or the "Expert- System-only" treatment, after which they were given a set of transfer pricing cases to solve. A total of 23 cases were assigned during the learning period. The assigned cases became progressively more difficult in order to expose the subjects to more complex situations.

\section{Post-test}

A post-test was given upon completion of the experimental cases. This occurred one week after the pre-test and two days after the subjects completed the experimental cases. Identical post-tests were given to all three sections consisting of two parts: (1) the same ten questions used in the pre-test to measure declarative knowledge, although in a different order from the pre-test, and (2) seven transfer pricing problems to measure their new levels of procedural knowledge. Again, the questions and problems were taken from test-banks and problems previously used in managerial accounting courses. The post-test problems covered the different situations that the students had been exposed to in the pre-test and during the learning phase of the experiment. The post-test was completed by all students without the use of any type of decision aid, which ensured that learning, and not tool use, was being measured. 
Independent and Dependent Variables

Five variables were included in this study: teaching method, personality traits, students' perceptions, and two variables that measured the development of the subjects' knowledge. With respect to teaching method, two sections received instruction using a matrix approach to transfer pricing. Two sections were provided with a transfer-pricing expert system. The operation of the expert system and its use in solving problems was demonstrated in class by the instructor. One section received instruction in the matrix approach only ( INST, 21 subjects), another section received the expert system only (ES, 41 subjects), while the third section was provided with both the transfer pricing expert system and a discussion of the matrix approach (ESINST, 35 subjects). Several copies of the expert system were available for students to use in the computer lab.

Students ${ }^{0}$ personality traits were measured using the Myers-Briggs Types Indicator (MBTI) Form G, classifying each student as $S$ (sensing) or $\mathrm{N}$ (intuitive), $\mathrm{T}$ (thinking) or $\mathrm{F}$ (feeling), $\mathrm{E}$ (extroverted) or I (introverted), and $\mathrm{P}$ (perceiving) or $\mathbf{J}$ (judging).

The students ${ }^{\circ}$ perceptions about the teaching methods were measured by their responses to three statements at the end of the experiment. Using a seven-point-scale, students agreed or disagreed with statements that they learned a lot, the assignment was worthwhile, and the assignment was entertaining.

The two variables that measured the development of the subjects' knowledge over the course of the experiment were the percentage of correct answers on the multiple-choice post-test (declarative, factual knowledge) and the percentage of correct answers on the post-test transfer pricing problems (procedural, how-to knowledge). Cook and Campbell (1979) note that gain score analysis, the use of the difference between pre-test and post-test scores as the dependent variable, is generally less precise than covariance analysis; therefore, pre-test scores were used as covariates in the ANCOVA models.

\section{Results of the Study}

A Tukey HSD test indicated that demographic factors were not significantly different across treatment groups. Tables 1 and 2 provide the mean pre-test and post-test scores along with the difference for each treatment group for declarative and procedural knowledge. The mean post-test scores for the Expert-System-withInstruction group and the Instruction-only group are better than the score of the Expert-Systemonly group for declarative knowledge. Subjects generally exhibited an increase in perceptual cohesiveness (reduced standard deviation) as a result of treatment application in those two groups also. With regard to procedural knowledge, the mean post-test scores for the Expert-System-only group and Expert-System-with-Instruction group are better than the score for the Instruction-only group. These findings are consistent with Odom and Pourjalali (1996).

Additionally, the personality traits affected the development of both declarative and procedural knowledge and the significant interactions among variables provide evidence that personality traits influence the development of declarative and procedural knowledge differently, depending on the teaching method utilized.

As previously mentioned, students' perceptions were determined by their responses to three statements at the completion of the experiment. Their responses to 1) learned a lot from the assignment, 2) found the assignment worthwhile, and 3) found the assignment entertaining, were marked on a Lacerate scale from 1 to 7 , with "1" indicating strong agreement and "7" indicating strong disagreement. Table 3 presents the averages broken down by instructional method and personality traits.

Hypothesis 1 states that the perception of an assignment is not different when an expert system is used as a teaching method. Table 3 
Table 1

Mean Declarative Knowledge Pre-test and Post-test Scores (standard deviation)

\begin{tabular}{||lccl||}
\hline \hline Treatment & Pre-test & Post-test & Difference \\
\hline Expert System & 4.486 & 7.571 & 3.085 \\
with Instruction & $(1.869)$ & $(0.815)$ & \\
& & & \\
Instruction & 4.571 & 7.476 & 2.905 \\
& $(1.720)$ & $(1.365)$ & \\
& & 6.927 & 1.878 \\
\hline
\end{tabular}

Table 2

Mean Procedural Knowledge Pre-test and Post-test Scores (standard deviation)

\begin{tabular}{|lcll||}
\hline Treatment & Pre-test & Post-test & Difference \\
\hline Expert System & 6.400 & 22.800 & 16.400 \\
with Instruction & $(4.001)$ & $(2.374)$ & \\
& & & \\
Instruction & 6.810 & 22.143 & 15.333 \\
& $(3.737)$ & $(3.395)$ & \\
Expert System & 6.585 & 23.659 & 17.0740 \\
& $(4.260)$ & $(1.334)$ & \\
\hline
\end{tabular}

shows that the Instruction-only group's average for "learned a lot" and "worthwhile assignment" was significantly lower than the averages for groups that used the expert system (see All row; lower scores signify greater agreement). This suggests that, on average, students perceive that learning through traditional instruction is more appealing. However, the mean test scores reported earlier in Tables 1 and 2 reveal that the Instruction-only group did not have the highest scores on the post-tests. Hence, the Instructiononly students' perceptions for "learned a lot" and "worthwhile assignment" were not confirmed by their performance outcomes. This finding may be related to the fact that students are accustomed to classroom instruction and that using an expert system may have been troublesome for them. The expert system may have made the students feel insecure as to whether they were learning, due to apprehension about using a different instructional method. These findings support the rejection of hypothesis 1 .

A closer inspection of Table 3 also reveals that different personality traits indicate different perceptions of the assignment. Even with the small number of subjects, there are significant differences among different personality groups in answering the question of "worthwhile assignment." In the Expert-System-withInstruction group, 'introverted' individuals ranked "worthwhile assignment," 3.15 on average, while 'extroverted' subjects ranked the same statement, on average, 2.11. The 'extroverted' individuals found the combination teaching method more worthwhile than the 
Table 3

Perception by Teaching Method and Personality Traits

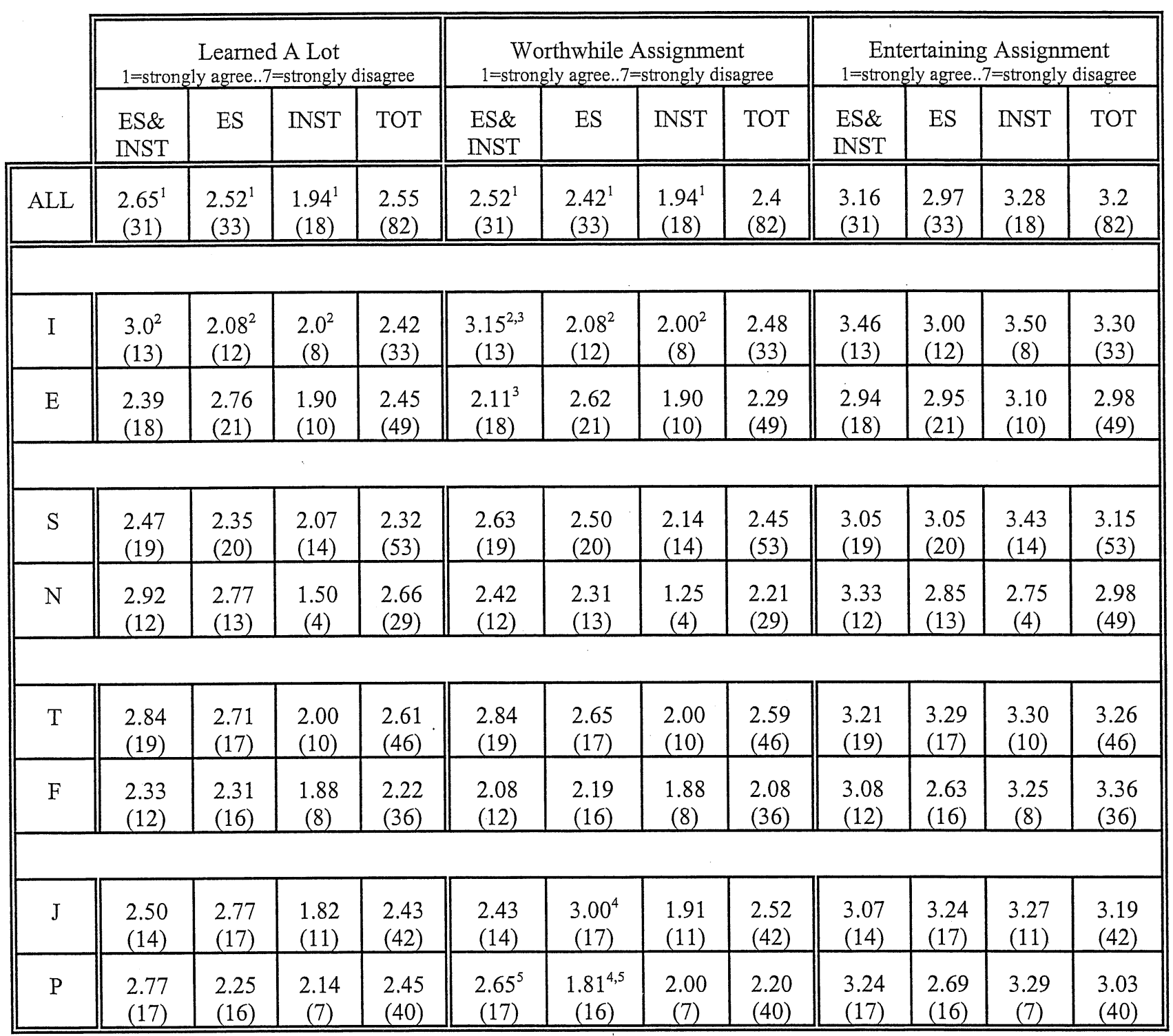

Notes: ${ }^{1}$ The average in INST is significantly different from the averages for ES and ES\&INST $(p<.05)$.

2 The average for I in INST is significantly different from the averages for ES and ES\&INST $(p<.05)$.

${ }^{3}$ The average in I is significantly different from the average in $E(p<.05)$.

${ }^{4}$ The average in $\mathrm{J}$ is significantly different from the average in $\mathrm{P}(\mathrm{p}<.05)$.

${ }^{5}$ The average for $\mathrm{P}$ in ES is significantly different from the averages for ES\&INST ( $p<.05$ ). 
'introverted' individuals. Additionally, looking solely at the 'introverted' subjects, their perception of whether they "learned a lot" and "worthwhile assignment" is significantly different between the combination teaching method and each of the other two teaching methods. The 'introverts' apparently did not like the combination method, preferring the individual methods which were probably less threatening.

One other relationship that is statistically significant example can be seen on the "worthwhile assignment" question for the Expert-System-only group. 'Judging' individuals ranked "worthwhile assignment" 3.00 on average, while 'perceiving' subjects ranked the same question, on average, 1.81. In other words, the 'perceiving' individuals found the expert system teaching method to be more worthwhile than did the 'judging' individuals. Additionally, looking specifically at the 'perceiving' row on Table 3, a significant difference is found between the Expert-System-with-Instruction and the ExpertSystem-only group with the later group feeling that the assignment was more worthwhile. . These findings are in line with expectations and support the rejection of hypothesis 2 .

Table 4 shows the effect of students' personality traits and the teaching method on the students' perceptions of the assignment. Based on these findings, we conclude that the method of instruction (Expert-Systems-only, ExpertSystems-with-Instruction, and Instruction-only) significantly affects the students' perceptions for each of the three statements (see METHOD values for all three Panels), further support for the rejection of hypothesis 1 . The results of the test for the association between students' perceptions and their personality traits are also provided in Table 4. As expected the results show that the students' personality traits affected their perceptions about the assignment (see STYLE values for all three Panels), providing further support for rejecting the second hypothesis.

Hypothesis 3 states that the students' perceptions of a teaching method made no differ- ence in their knowledge development. The students' perceptions (as measured by responses to the three statements discussed earlier) along with their personality traits were included as independent variables in ANCOVA models constructed to explain students' scores. Table 5 presents the test for declarative knowledge, based on the student's scores on the post-test multiple choice questions. The pre-test scores were used as a covariate in the model. As the data indicate, the perception variable "Entertaining Assignment" was significant in the development of declarative knowledge. Similar findings for the development of procedural knowledge are found in Table 6.

\section{Summary and Conclusion}

Recent interest in the development and use of expert systems and computer-assisted instruction as pedagogical tools has resulted in a need for research into the effectiveness of such instructional methods. Odom and Pourjalali (1996) examine the effect of personality traits on knowledge development, both separately and in cohort with a specific teaching method. Their results indicate that the teaching method as well as personality traits affect the development of declarative and procedural knowledge. In addition, their results show that certain personalities perform better in response to certain teaching methods. Boer and Livnat (1990) found that students' perceptions of a teaching method can also influence their performance in the classroom.

This study supports and extends these findings by exploring a linkage between personality traits and perception. Results indicate that students' perceptions are significantly related to the their personality traits. The STYLE variable in Table 4, representing the four different personality aspects, was found to significantly affect each of the three perception variables in the study. This linkage between personality traits and perception indicates that the subjects' perception of the teaching methods are influenced by preferences that are ingrained in the subjects. 
Table 4

ANCOVA Analysis of Students' Perceptions of Teaching Methods

\begin{tabular}{|c|c|c|c|c|c|}
\hline \multirow{4}{*}{ PANELA: } & Source & $\begin{array}{l}\text { Sum-of- } \\
\text { Squares }\end{array}$ & DF & $\begin{array}{l}\text { Mean- } \\
\text { Squares }\end{array}$ & $\mathrm{P}$ \\
\hline & METHOD & 85.019 & 2 & 42.509 & 0.002 \\
\hline & STYLE & 50.104 & 3 & 16.701 & 0.058 \\
\hline & GENDER & 0.796 & 1 & 0.796 & 0.725 \\
\hline \multirow{5}{*}{$\begin{array}{l}\text { ANCOVA Analysis of the } \\
\text { response to Statement 1, } \\
\text { "Learned A Lot" }\end{array}$} & METHOD & & & & \\
\hline & *STYLE & 72.651 & 6 & 12.108 & 0.093 \\
\hline & & 10.083 & 2 & 5.041 & 0.457 \\
\hline & *GENDER & 35.537 & 3 & 11.846 & 0.145 \\
\hline & ERROR & 413.263 & 65 & 6.358 & \\
\hline \multirow{4}{*}{ PANEL B: } & Source & $\begin{array}{l}\text { Sum-of- } \\
\text { Squares }\end{array}$ & DF & $\begin{array}{l}\text { Mean- } \\
\text { Squares }\end{array}$ & $\mathrm{P}$ \\
\hline & METHOD & 68.348 & 2 & 34.174 & 0.005 \\
\hline & STYLE & 69.303 & 3 & 23.101 & 0.013 \\
\hline & GENDER & 1.572 & 1 & 1.572 & 0.609 \\
\hline \multirow{5}{*}{$\begin{array}{l}\text { ANCOVA Analysis of the } \\
\text { response to Statement } 2 \\
\text { "Worthwhile Assignment" }\end{array}$} & METHOD & & & & \\
\hline & *STYLE & 58.191 & 6 & 9.699 & 0.152 \\
\hline & $\begin{array}{l}\text { METHOD } \\
\text { *GENDER } \\
\text { STYLE }\end{array}$ & 10.718 & 2 & 5.359 & 0.411 \\
\hline & *GENDER & 30.465 & 3 & 10.155 & 0.174 \\
\hline & ERROR & 386.257 & 65 & 5.942 & \\
\hline \multirow{9}{*}{$\begin{array}{l}\text { ANCOVA Analysis of the } \\
\text { response to Statement } 3 \\
\text { "Entertaining Assignment" }\end{array}$} & Source & $\begin{array}{l}\text { Sum-of- } \\
\text { Squares }\end{array}$ & $\mathrm{DF}$ & $\begin{array}{l}\text { Mean- } \\
\text { Squares }\end{array}$ & $\mathrm{P}$ \\
\hline & METHOD & 71.802 & 2 & 35.901 & 0.035 \\
\hline & STYLE & 106.22 & 3 & 35.406 & 0.021 \\
\hline & GENDER & 0.395 & 1 & 0.395 & 0.844 \\
\hline & METHOD & & & & \\
\hline & $\begin{array}{l}\text { *STYLE } \\
\text { METHOD }\end{array}$ & 110.00 & 6 & 18.499 & 0.109 \\
\hline & $\begin{array}{l}\text { *GENDER } \\
\text { STYLE }\end{array}$ & 22.288 & 2 & 11.144 & 0.340 \\
\hline & ${ }^{*}$ GENDER & 52.644 & 3 & 17.548 & 0.170 \\
\hline & ERROR & 660.905 & 65 & 10.168 & \\
\hline
\end{tabular}

Notes: METHOD = Three sections of the course. One section was given Expert System only, another section Instruction only, and the last one Instruction and Expert Systems.

STYLE $\quad=$ Represents four aspects of personality traits; EI, SN, TF, and JP.

GENDER $\quad=$ Represents the student gender. 
Table 5

ANCOVA Analysis of Post-test Multiple Choice Scores

(Declarative Knowledge)

\begin{tabular}{|lrrrr||}
\hline \hline Source & \multicolumn{1}{c}{$\begin{array}{l}\text { Sum-of- } \\
\text { squares }\end{array}$} & DF & F-Ratio & P \\
\hline Pre-test & 282.91 & 1 & 86.34 & 0.00 \\
Learned a lot & 7.89 & 1 & 2.41 & 0.13 \\
Worthwhile assignment & 8.03 & 1 & 2.45 & 0.12 \\
Entertaining assignment & 40.89 & 1 & 12.48 & 0.00 \\
Extroverted/Introverted (EI) & 22.52 & 1 & 6.87 & 0.01 \\
Sensing/Intuitive (SN) & 10.70 & 1 & 3.26 & 0.07 \\
Thinking/Feeling (TF) & 4.29 & 1 & 1.31 & 0.26 \\
Perceiving/Judging (PJ) & 7.84 & 1 & 2.39 & 0.13 \\
& & & & \\
ERROR & 288.79 & 74 & & \\
\hline
\end{tabular}

Table 6

ANCOVA Analysis of Post-test Case Scores (Procedural Knowledge)

\begin{tabular}{|lrrrr||}
\hline \hline Source & \multicolumn{1}{c}{$\begin{array}{l}\text { Sum-of- } \\
\text { squares }\end{array}$} & DF & F-Ratio & P \\
\hline Pre-test & 1542.86 & 1 & 35.41 & 0.00 \\
Learned a lot & 10.42 & 1 & 0.24 & 0.63 \\
Worthwhile assignment & 9.06 & 1 & 0.21 & 0.65 \\
Entertaining assignment & 524.16 & 1 & 12.03 & 0.00 \\
Extroverted/Introverted (EI) & 192.24 & 1 & 4.41 & 0.04 \\
Sensing/Intuitive (SN) & 149.93 & 1 & 3.44 & 0.07 \\
Thinking/Feeling (TF) & 645.79 & 1 & 14.82 & 0.00 \\
Perceiving/Judging (PJ) & 159.23 & 1 & 3.65 & 0.06 \\
& & & & \\
ERROR & 3224.22 & 74 & & \\
\hline
\end{tabular}

Furthermore, the students' preferences were found to affect performance as measured by development of declarative and procedural knowledge. Specifically, when the students' post-test scores were controlled for, using their pre-test scores and personality traits, their attitudes toward "finding the assignment entertaining" significantly affected their learning.

Another interesting finding was that the students' perceptions of a teaching method may not always harmonize with their performance in the class. For two of the perception variables, "learned a lot" and "worthwhile assignment," the students in the Instruction-only group were significantly more agreeable than the students in the other two teaching method groups, ExpertSystem-only and Expert-System-with-Instruction. However, the data shows that these perceptions are not in line with actual performance. The Instruction-only group's mean gain scores between pre-tests and post-tests for both declarative and procedural knowledge are no better than the other two groups, and are actually the lowest of 
the three groups for procedural knowledge.

These findings, thus, suggest that although the students' perceptions about a teaching method can affect their performance in a class, such perceptions can not be used to measure how worthwhile and successful a teaching method is-at least at the procedural knowledge level. This should provide a warning for instructors who use student evaluations of a teaching method without considering factors such as the possibility that the students are unable to accurately evaluate teaching methods due in part to differences in personality traits.

\section{Implications for Future Research}

Additional research is needed to explain why the effect of perception is different for the two types of knowledge acquisition. Furthermore, research is needed to find out if students are negative about all new teaching methods or only the ones that use new technology. Another interesting extension of this study is to examine through a longitudinal study how long students remain negative to new methods of instruction (expert systems in this example). Lastly, the linkage between personality traits and perception needs to be further explored to determine specifically what teaching methods are desired by particular personality types. If the correct matches can be found, the students' perceptions of the teaching methods should improve and, this should lead to improved performance.

The limitations of this project are the general limitations related to a laboratory experiment. The use of a single instructor for all subjects removes the possibility that students' responses were instructor-biased; however, it may also limit generalizability. Furthermore, this study is limited to only one university and one semester of instruction involving a relatively small number of students. This limitation would be overcome if the number of observations were increased by including several semesters and more than one university.
Footnotes

1. Missing data reduced the number of observations to eighty-two for testing of hypotheses.

\section{References}

1. Barbera, Anthony T., (1987). Artificial Intelligence in Accounting: The Future Has Arrived, Review of Business, pp. 17-21.

2. Boer, G. B., and J. Livnat, (1990). Using Expert Systems to Teach Complex Accounting Issues. Issues in Accounting Education, pp. 108-119.

3. Booth, P., and H. Winzar, (1993). Personality Biases of Accounting Students: Some Implications for Learning Style Preferences. Accounting and Finance, pp. 109120.

4. Briggs, K., and I. Myers, (1990). MyersBriggs Type Indicator Form $G$ Booklet. Palo Alto, CA: Consulting Psychologists Press.

5. Cook, T. D. and D. T. Campbell, (1979). Quasi-Experimentation: Design \& Analysis Issues for Field Settings. Boston: Houghton Mifflin Company.

6. Gagne, E. D., (1985) The Cognitive Psychology of School Learning, Boston: Little Brown and Company.

7. Jung, C. G., (1923) Psychological Types, London: Routledge and Kegan Paul.

8. Myers, I. B., (1987), Introduction to Type: A Description of the Theory and Applications of the Myers-Briggs Type Indicator. Palo Alto, CA: Consulting Psychologists Press.

9. Myers, I. B., and M. H. McCaulley, (1989), Manual: $A$ Guide to the Development and Use of the Myers-Briggs Type Indicator. Palo Alto, CA: Consulting Psychologists Press.

10. Odom, M. D. and H. Pourjalali, (1996). Expert Systems Versus Traditional Methods for Teaching Accounting Issues. Developments in Business Simulation \& Experiential Exercises, pp. 131-35. 
11. Ott, R. L., M. H. Mann, and C. T. Moores, (1990). An Empirical Investigation into the Interactive Effects of Student Personality Traits and Method of Instruction (Lecture or CAI) on Student Performance in Elementary Accounting. Journal of Accounting Education, pp. 17-35.

12. Thomas, M. F., (1991), A Matrix Approach to Transfer Pricing. Journal of Accounting Education. pp. 137-148.

13. Waner, K., and L. Echternacht, (1993). Using the Myers-Briggs Type Indicator to Compare Personality Types of Business Teachers Who Teach Office Occupations with Personality Types of Office Professionals. The Delta Pi Epsilon Journal, pp. 53-68. 